\title{
Genetic characterization of Rhipicephalus sanguineus (sensu lato) ticks from dogs in Portugal
}

\author{
Filipe Dantas-Torres ${ }^{1,2^{*}}$, Carla Maia ${ }^{3,4}$, Maria Stefania Latrofa² ${ }^{2}$ Giada Annoscia² ${ }^{2}$ Luís Cardoso ${ }^{5}$ \\ and Domenico Otranto ${ }^{2}$
}

\begin{abstract}
Background: The taxonomic status of the brown dog tick Rhipicephalus sanguineus (sensu stricto) is a subject of ongoing debate; there is a consensus that populations of this tick species should be referred to as $R$. sanguineus (sensu lato) until its taxonomic status is resolved. Recent genetic studies revealed the existence of more than one lineage of $R$. sanguineus (s.l.) in temperate countries. In this study, we assessed the genetic identity of ticks collected from rural dogs living in several areas located in all major geographical regions of Portugal.

Methods: A total of 347 ticks were collected from rural dogs living in different regions of Portugal. These ticks were morphologically identified and partial mitochondrial 165 rRNA gene sequences ( 300 bp) were obtained from representative specimens.

Results: The ticks were morphologically identified as Ixodes ricinus (seven males and 27 females), Rhipicephalus bursa (one male), Rhipicephalus pusillus (one female) and R. sanguineus (s.l.) (two larvae, 101 nymphs, 108 males and 100 females). Partial mitochondrial $16 \mathrm{~S}$ rRNA gene sequences were obtained from 58 R. sanguineus (s.l.) specimens, and all of them were genetically identified as belonging to the so-called temperate lineage of $R$. sanguineus (s.l.)

Conclusions: These results strongly suggest that the temperate species of $R$. sanguineus (s.l.) is the only representative of this tick group found on dogs in Portugal. It also adds weight to the hypothesis that Rhipicephalus turanicus is not present in this country, although further investigations are necessary to confirm this.
\end{abstract}

Keywords: Brown dog ticks, Rhipicephalus, Dogs, Genetics, Morphology, Portugal

\section{Background}

Ticks are important vectors of pathogens to companion animals, livestock and humans. Current global changes (e.g. climate changes, deforestation, changes in land use, urbanization, increased trade and travel) are affecting animal host populations worldwide [1], favouring the establishment of ticks and their associated pathogens into previously free areas.

The brown dog tick Rhipicephalus sanguineus (sensu stricto) is a species of major medical and veterinary significance [2]. The taxonomy of this tick species is a subject of

\footnotetext{
*Correspondence: filipe.dantas@cpqam.fiocruz.br

'Department of Immunology, Aggeu Magalhães Institute, Oswaldo Cruz

Foundation (Fiocruz), Recife, Pernambuco 50740-465, Brazil

${ }^{2}$ Department of Veterinary Medicine, University of Bari, 70010, Valenzano,

Bari, Italy

Full list of author information is available at the end of the article
}

an ongoing debate, mainly because there is no typematerial and no bona fide morphological description [3, 4]. For this reason, there is a consensus that populations of this tick species should be referred to as $R$. sanguineus (sensu lato) (s.l.) until its taxonomic status is resolved.

Genetic studies have consistently reported the existence of two well-defined lineages within " $R$. sanguineus": the southern lineage (also referred to as temperate species/lineage) and the northern lineage (tropical species/ lineage) [5-11]. Available scientific data indicate that the situation regarding the taxonomic status of $R$. sanguineus (s.l.) in Europe is even more complicated. In particular, a higher diversity of cryptic species seems to occur in the Mediterranean region [8] as compared with Latin America [5-7]. Furthermore, the diversity of Rhipicephalus spp. appears to increase from West to 
East in the Eurasia [8]. Indeed, the so-called temperate species/lineage (also referred to as "Rhipicephalus sp. II" by Dantas-Torres et al. [8]) of $R$. sanguineus (s.l.) appears to be the only representative of this species group in western European countries such as Portugal and Spain [8]. On the other hand, additional operational taxonomic units (OTUs) (e.g. Rhipicephalus sp. I) and/or species (e.g. Rhipicephalus turanicus) are apparently present in countries such as Italy and Greece.

A considerable amount of genetic data have been generated from $R$. sanguineus (s.l.) ticks in recent years. However, only few studies have assessed the genetic variability of ticks from different regions within the same country (e.g. Brazil; [5]), in order to define which tick species/lineage is present. In this study, we assessed the genetic identity of $R$. sanguineus (s.l.) ticks collected from dogs from all major geographical regions of Portugal to assess two hypotheses: (i) $R$. turanicus is not found on dogs from Portugal; and (ii) the temperate species/lineage is the only representative of the $R$. sanguineus (s.l.) group infesting dogs in this country.

\section{Methods}

From June 2013 to April 2014, ticks $(n=347)$ were collected from rural dogs living in different regions of Portugal (Table 1). The owners physically restrained dogs and ticks were collected manually and placed in labelled vials containing $70 \%$ ethanol. Identification was carried out under a stereomicroscope using morphological keys [12-14]. In particular, we considered all the morphological characters detailed in Dantas-Torres et al. [8], such as idiosoma, dorsal scutum, basis capituli, hypostomal dentition, female porose areas, female genital opening, spiracular plates, dorsal tail of spiracular plates, lateral and postmediam grooves, cervical pits, cervical fields, internal and external cervical grooves,

Table 1 Areas of Portugal surveyed in this study

\begin{tabular}{ll}
\hline Areas & Geographical coordinates \\
\hline Alijó & $41^{\circ} 17^{\prime} 0^{\prime \prime} \mathrm{N}, 7^{\circ} 28^{\prime} \mathrm{O}^{\prime \prime} \mathrm{W}$ \\
Azores & $37^{\circ} 44^{\prime} 28^{\prime \prime} \mathrm{N}, 25^{\circ} 40^{\prime} 32^{\prime \prime} \mathrm{W}$ \\
Beja & $38^{\circ} 1^{\prime} \mathrm{O}^{\prime \prime} \mathrm{N}, 7^{\circ} 52^{\prime} \mathrm{O}^{\prime \prime} \mathrm{W}$ \\
Bragança & $41^{\circ} 48^{\prime} 20^{\prime \prime} \mathrm{N}, 6^{\circ} 45^{\prime} 42^{\prime \prime} \mathrm{W}$ \\
Faro & $37^{\circ} 2^{\prime} 0^{\prime \prime} \mathrm{N}, 7^{\circ} 55^{\prime} \mathrm{O}^{\prime \prime} \mathrm{W}$ \\
Gondomar & $41^{\circ} 9^{\prime} \mathrm{O}^{\prime \prime} \mathrm{N}, 8^{\circ} 32^{\prime} \mathrm{O}^{\prime \prime} \mathrm{W}$ \\
Gouveia & $40^{\circ} 30^{\prime} \mathrm{O}^{\prime \prime} \mathrm{N}, 7^{\circ} 36^{\prime} \mathrm{O}^{\prime \prime} \mathrm{W}$ \\
Guarda & $40^{\circ} 32^{\prime} \mathrm{O}^{\prime \prime} \mathrm{N}, 7^{\circ} 20^{\prime} \mathrm{O}^{\prime \prime} \mathrm{W}$ \\
Lourinhã & $39^{\circ} 15^{\prime} \mathrm{O}^{\prime \prime} \mathrm{N}, 9^{\circ} 19^{\prime} \mathrm{O}^{\prime \prime} \mathrm{W}$ \\
Madeira & $32^{\circ} 39^{\prime} 4^{\prime \prime} \mathrm{N}, 16^{\circ} 54^{\prime} 35^{\prime \prime} \mathrm{W}$ \\
Porto & $41^{\circ} 9^{\prime} 0^{\prime \prime} \mathrm{N}, 8^{\circ} 36^{\prime} 40^{\prime \prime} \mathrm{W}$ \\
Sabugal & $40^{\circ} 21^{\prime} 0^{\prime \prime} \mathrm{N}, 7^{\circ} 5^{\prime} \mathrm{O}^{\prime \prime} \mathrm{W}$ \\
\hline
\end{tabular}

marginal lines, male adanal and accessory plates, male caudal process, spur on trochanter I, and body colour. Ticks morphologically compatible with the description of Walker et al. [13] for " $R$. sanguineus" were referred to as " $R$. sanguineus (s.l.)".

A total of 61 ticks, including at least one tick from each geographical site, were selected for genetic analysis. DNA extraction was performed using a commercial kit (DNeasy Blood \& Tissue Kit, Qiagen GmbH, Hilden, Germany), in accordance with the manufacturer's instructions. Partial mitochondrial 16S rRNA ( 300 bp) gene sequences were generated and analysed. Primers and PCR conditions have been described elsewhere [5]. Each reaction consisted of $4 \mu \mathrm{l}$ of tick genomic DNA and $46 \mu \mathrm{l}$ of PCR mix containing $2.5 \mathrm{mM}$ $\mathrm{MgCl}_{2}, 10 \mathrm{mM}$ Tris- $\mathrm{HCl}(\mathrm{pH} 8.3)$, and $50 \mathrm{mM} \mathrm{KCl}$, $250 \mu \mathrm{M}$ of each dNTP, $50 \mathrm{pmol}$ of each primer and $1.25 \mathrm{U}$ of AmpliTaq Gold (Applied Biosystems, California, USA). Approximately $100 \mathrm{ng}$ of genomic DNA (with the exception of the no-template control) were added to each PCR. Amplified products were examined on $2 \%$ agarose gels stained with GelRed (VWR International PBI, Milan, Italy) and visualized on a GelLogic 100 gel documentation system (Kodak, New York, USA).

Amplified products were purified and sequenced, in both directions using the same primers as for PCR, employing the Big Dye Terminator v.3.1 chemistry in a 3130 genetic analyzer (Applied Biosystems, California, USA). The 16S rRNA gene sequences were aligned using ClustalW program [15] and compared with those available in GenBank using the BLASTn tool (http:// blast.ncbi.nlm.nih.gov/Blast.cgi). The percentage of nucleotide variation (pairwise comparison - Pwc) amongst all haplotypes identified was calculated using the Kimura 2-parameter substitution model with gamma distributed rates among sites [16], implemented in the MEGA 6 software [17].

For phylogenetic analyses, we included sequences from each haplotype obtained herein as well as individual or consensus sequences (GenBank accession numbers: KC243835-KC243838, KC243843-KC243847, KC 243851-KC243854, КC243855, КC243856-KC243867 and KC243871) for the other Rhipicephalus spp. (for more details, see Additional file 1: Table S1) available from a previous study [8]. In particular, consensus sequences from selected tick species were generated after alignment with ClustalW program [15] and using the BioEdit software [18]. A homologous gene sequence from Ixodes ricinus (GenBank JF928527) was used as the outgroup. Phylogenetic relationships were inferred by maximum likelihood analysis [16] with the general time reversible model in MEGA 6 [17]; bootstrap values are based on 8,000 replicates. 


\section{Results}

Morphologically, ticks were identified as $I$. ricinus (seven males and 27 females), Rhipicephalus bursa (one male), Rhipicephalus pusillus (one female), and $R$. sanguineus (s.l.) (two larvae, 101 nymphs, 108 males and $100 \mathrm{fe}-$ males). Most (all but 12) R. sanguineus (s.l.) ticks resembled (e.g. large, dark-coloured ticks, with males presenting elongated spiracular plates with narrow dorsal tails and females presenting typical U-shaped genital opening) the so-called temperate species (data not shown). Morphological variations in ticks collected from different regions and even within the same region were noticeable. In particular, some male ticks (ten from Bragança and two from Lourinhã) presented spiracular plates with short and large dorsal tails, which could resemble those of $R$. turanicus.

With regard to genetic data, a total of 59 partial $16 \mathrm{~S}$ rRNA gene sequences were obtained; for two ticks no amplification was obtained. One of these sequences shared 98\% identity with a sequence of $R$. pusillus available in GenBank (KC243855). The remaining 58 sequences were from ticks identified as $R$. sanguineus (s.l.) and were all genetically assigned to the temperate species/lineage, including specimens resembling morphologically $R$. turanicus (see Additional file 1: Table S1). BLAST analysis revealed that the eight haplotypes identified shared high nucleotide identity (99-100\%) with those of Rhipicephalus sp. II (= temperate species/ lineage) available in GenBank (KC243843-KC243846). Indeed, one haplotype was identical to haplotype II of Rhipicephalus sp. II previously identified in Portugal and in northern Italy (GenBank KC243844).

The new representative sequence types were named as haplotypes VI-XII. The haplotype VI was the most prevalent haplotype $(n=30 ; 51.7 \%)$ identified and found in all surveyed areas (Table 2), followed by haplotype II ( $n=10 ; 17.2 \%)$. The nucleotide sequence variation, upon pairwise comparison, ranged from zero to $1.1 \%$ (mean $0.7 \%)$, and a high nucleotide difference (1.1\%) was recorded between haplotypes II and X, which were obtained from specimens collected in the same area (Alijó). All representative new haplotypes obtained are available in the GenBank database under accession numbers: KY216135-KY216141.

Phylogenetic analysis was concordant in clustering all haplotypes identified in the same clade with the consensus sequence of the temperate species/lineage, supported by a high bootstrap value, to the exclusion of other $R h i$ picephalus spp. (Fig. 1).

\section{Discussion}

In this study, all $R$. sanguineus (s.l.) ticks collected from rural dogs living in different regions and areas of Portugal were morphologically compatible with the so-
Table 2 Ticks and haplotypes identified in areas of Portugal

\begin{tabular}{|c|c|c|c|}
\hline \multirow[t]{2}{*}{ Area } & \multirow{2}{*}{$\begin{array}{l}\text { Nymph } \\
\text { (n/ } \\
\text { haplotype) }\end{array}$} & \multicolumn{2}{|c|}{ Adult (n/haplotype) } \\
\hline & & Male & Female \\
\hline Alijó & - & $1 / \mathrm{Nl} ; 1 / \mathrm{ll} ; 1 \mathrm{NII}$ & $1 / \mathrm{Nl} ; 1 / \mathrm{Il} ; 1 \mathrm{NIl} ; 2 / \mathrm{X}$ \\
\hline Azores & $1 / I X$ & $2 \mathrm{Nl} ; 1 / \mathrm{IX}$ & - \\
\hline Beja & $1 / \mathrm{Nl}$ & - & $2 \mathrm{NI}$ \\
\hline Bragança & - & 2NI; 1NII; 1/XI & $1 / \mathrm{Vl} ; 1 \mathrm{NII}$ \\
\hline Faro & - & $1 / \mathrm{Nl} ; 1 / \mathrm{XI}$ & $1 \mathrm{NI}$ \\
\hline Gondomar & - & $1 / \mathrm{Nl} ; 1 / \mathrm{Il} ; 1 \mathrm{NII}$ & $1 \mathrm{NIII}$ \\
\hline Gouveia & $1 \mathrm{Nl} ; 3 / \mathrm{II}$ & - & - \\
\hline Guarda & $2 \mathrm{NI}$ & $1 / \mathrm{NI}$ & $1 \mathrm{NI}$ \\
\hline Lourinhã & - & 1Nl; 1NI & $2 \mathrm{Nl} ; 1 / \mathrm{II}$ \\
\hline Madeira & $1 \mathrm{NI}$ & - & - \\
\hline Porto & $1 \mathrm{NIII}$ & $1 / \mathrm{NI} ; 3 \mathrm{NIII}$ & $1 / \mathrm{II} ; 1 / \mathrm{NIII}$ \\
\hline Sabugal & - & $2 \mathrm{NI} ; 1 / \mathrm{II}$ & $5 / \mathrm{Nl} ; 1 / \|$ \\
\hline
\end{tabular}

called temperate species/lineage. Twelve male ticks presented spiracular plates with large and short dorsal tails, resembling those of $R$. turanicus (data not shown), but all of them were genetically confirmed as indistinct from the temperate species/lineage. Our data further indicate that the "classic" morphological identification of $R$. turanicus based on only spiracular plates does not correlate with molecular findings. This also indicates that ticks previously identified as $R$. turanicus in Portugal (e.g. [19]) were actually $R$. sanguineus (s.l.) (temperate species/lineage), as already suggested by Santos-Silva et al. [20]. Indeed, our study indicates that the temperate species/lineage is the only representative of $R$. sanguineus (s.l.) infesting dogs in Portugal. The existence of a single species referred to as " $R$. sanguineus" with a high level of morphological polymorphism has been discussed elsewhere [20]. However, the existence of $R$. turanicus and even other species/lineages of $R$. sanguineus (s.l.) parasitizing other animal species in Portugal, particularly wildlife, cannot be ruled out and deserves further investigation.

Studies conducted in Latin America revealed the presence of two main lineages of $R$. sanguineus (s.l.) in the Neotropical region: tropical species (occurring from northern Mexico, Central America, and tropical areas of South America) and temperate species (found temperate and cold localities from the southern cone of South America) [5-7]. This notion is supported by more recent studies [8-10], indicating that ticks currently identified as " $R$. sanguineus" actually belong to at least two distinct species.

Because dogs are travelling with their owners (and with their ticks) around the world, the existence of two different lineages is intriguing. According to a recent study, the separation of these species seems to 


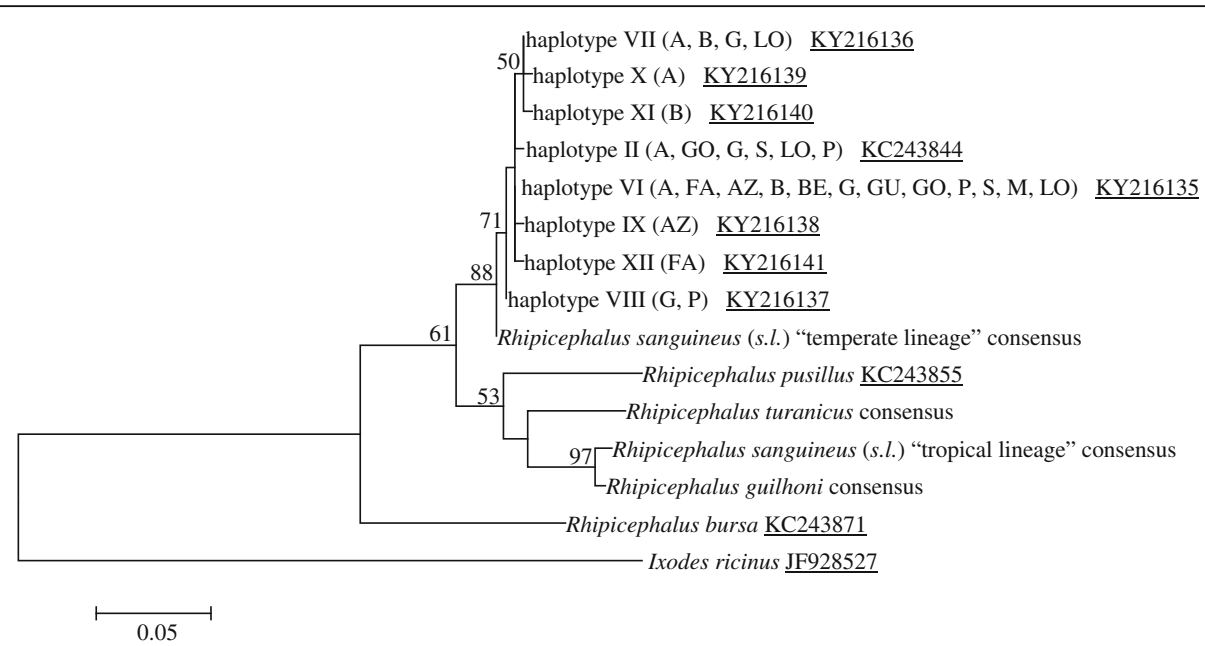

Fig. 1 Phylogeny of Rhipicephalus spp. inferred from 16S rRNA sequences. Maximum-parsimony tree based on 16S rRNA sequences generated herein as well as either single haplotype or consensus sequences of R. pusillus, R. bursa, R. sanguineus (s.l.) "temperate lineage" (= Rhipicephalus sp. II; Rhipicephalus sp. morphotype 2), R. turanicus, R. sanguineus (s.l.) "tropical lineage", and R. guilhoni. Geographical origins are reported in parentheses and GenBank accession numbers are underlined. Only bootstrap values $\geq 50 \%$ are indicated. Abbreviations: A, Alijó; AZ, Azores; BE, Beja; B, Bragança; FA, Faro; G, Gondomar; GO, Gouveia; GU, Guarda; LO, Lourinhã; M, Madeira; P, Porto; S, Sabugal

be driven by climate variables, particularly the annual mean temperature. Data indicate that the tropical species/lineage is present in areas with annual mean temperature $>20{ }^{\circ} \mathrm{C}$, whereas the temperate species/ lineage occurs in areas with annual mean temperature $<20{ }^{\circ} \mathrm{C}$ [11]. Whether ongoing climate changes will favour the establishment of populations of the tropical/lineage species in areas currently occupied exclusively by the temperate species/lineage and vice versa has yet to be determined.

The oldest record of a tick on a dog comes from ancient Egypt [21]. Ticks collected from a dog mummy found in a tomb surrounding a Roman fortress in El Dei were morphologically identified as belonging to the temperate species/lineage. Actually, the separation of the two main lineages of $R$. sanguineus (s.l.) might have occurred millions of years ago, as these species are reproductively isolated [22]. Moreover, differences in their complete mitochondrial genomes are estimated to be in the order of $\sim 10 \%$ [23].

Finally, the known circulation of several pathogens (e.g. Babesia vogeli, Cercopithifilaria sp. II, Ehrlichia canis, Hepatozoon canis, Rickettsia conorii and Rickettsia massiliae) among $R$. sanguineus (s.l.) ticks, dogs, cats and foxes in Portugal [24-28] indicates that the temperate species/lineage is playing a role in the transmission of these agents in this country. Interestingly, a study conducted by Moraes-Filho et al. [29] suggested that the absence or scarcity of cases of canine monocytic ehrlichiosis due to E. canis in the southern cone of South America might be a result of vector incompetence of the R. sanguineus (s.l.) ticks that are found on dogs in this part of South America. Whether the different haplotypes of the temperate lineage of $R$. sanguineus (s.l.) found in Portugal and other European countries present different vector capacities for each of the abovementioned pathogens has yet to be determined.

\section{Conclusions}

In conclusion, the data presented herein add weight to the hypotheses that the temperate species/lineage is the only representative of $R$. sanguineus (s.l.) in Portugal and that $R$. turanicus does not occur in this country.

\section{Additional file}

Additional file 1: Table S1. Sequences of Rhipicephalus spp. used in this study. (DOCX $16 \mathrm{~kb})$

\begin{abstract}
Acknowledgements
The authors would like to thank the veterinarians Ana Catarino (VetCoa Serviços Veterinários, Sabugal), Bruno Almeida (FMV-ULHT), Cláudia Ramos (IHMT-UNL), Duarte Diz-Lopes and Filipa T. Rodrigues (Clínica Veterinária VetSantiago, Bragança; and Consultório Veterinário de Vinhais), Joana Borges (Animed - Hospital Veterinário de Gondomar), João Mendes (FMV-ULHT), Mónica Coimbra (Clínica Veterinária Porto Seguro, Olhão), Nuno Alegria (Department of Veterinary Sciences, UTAD), Nuno Henriques (AVA - Assistência Veterinária de Alijó), Nuno Leal (Hospital Veterinário do Oeste, Lourinhã), Nuno Neves (Clube Animal, Beja) and Paulo Araújo (Vetfunchal - Centro Médico-Veterinário, Funchal) for tick collection. The work of C. Maia, D. Otranto and L. Cardoso was done under the frame of EurNegVec COST Action TD1303. This publication has been sponsored by Bayer Animal Health in the framework of the 12th CVBD World Forum Symposium.
\end{abstract} for funds to GHTM (UID/Multi/04413/2013). 


\section{Availability of data and materials}

The data supporting the conclusions of this article are included within the article.

\section{Authors' contributions}

FDT and CM conceived the study. FDT morphologically identified the ticks, analysed the results and wrote the manuscript. MSL and GA performed the genetic characterization of the ticks. LC and DO critically reviewed the manuscript. All authors read and approved the final manuscript.

\section{Competing interests}

The authors declare that they have no competing interests.

\section{Consent for publication}

Not applicable.

\section{Ethics approval and consent to participate}

The procedures were approved by the board of the Faculty of Veterinary Medicine (Universidade Lusófona de Humanidades e Tecnologias), as complying with the Portuguese legislation for the protection of animals (Decree-Law n 113/2013). Dog owners provided an oral consent allowing the inclusion of their dogs in the study.

\section{Author details}

'Department of Immunology, Aggeu Magalhães Institute, Oswaldo Cruz Foundation (Fiocruz), Recife, Pernambuco 50740-465, Brazil. ${ }^{2}$ Department of Veterinary Medicine, University of Bari, 70010, Valenzano, Bari, Italy. ${ }^{3}$ Current address: Global Health and Tropical Medicine, GHTM, Instituto de Higiene e Medicina Tropical, IHMT, Universidade Nova de Lisboa, UNL, Rua de Junqueira 100, 1349-008 Lisboa, Portugal. ${ }^{4}$ Faculty of Veterinary Medicine, Universidade Lusófona de Humanidades e Tecnologias, Campo Grande, 376, 1749-024 Lisboa, Portugal. ${ }^{5}$ Department of Veterinary Sciences, School of Agrarian and Veterinary Sciences, University of Trás-os-Montes e Alto Douro (UTAD), Vila Real, Portugal.

\section{Received: 25 November 2016 Accepted: 28 February 2017}

\section{Published online: 13 March 2017}

\section{References}

1. Dantas-Torres F. Climate change, biodiversity, ticks and tick-borne diseases: The butterfly effect. Int J Parasitol Parasites Wildl. 2015;4:452-61.

2. Dantas-Torres F, Chomel BB, Otranto D. Ticks and tick-borne diseases: a One Health perspective. Trends Parasitol. 2012;28:437-46.

3. Dantas-Torres F, Otranto D. Further thoughts on the taxonomy and vector role of Rhipicephalus sanguineus group ticks. Vet Parasitol. 2015;208:9-13.

4. Nava S, Estrada-Peña A, Petney T, Beati L, Labruna MB, Szabó MP, et al. The taxonomic status of Rhipicephalus sanguineus (Latreille, 1806). Vet Parasitol. 2015;208:2-8

5. Burlini L, Teixeira KR, Szabó MP, Famadas KM. Molecular dissimilarities of Rhipicephalus sanguineus (Acari: Ixodidae) in Brazil and its relation with samples throughout the world: is there a geographical pattern? Exp Appl Acarol. 2010;50:361-74.

6. Moraes-Filho J, Marcili A, Nieri-Bastos FA, Richtzenhain LJ, Labruna MB. Genetic analysis of ticks belonging to the Rhipicephalus sanguineus group in Latin America. Acta Trop. 2011;117:51-5.

7. Nava S, Mastropaolo M, Venzal JM, Mangold AJ, Guglielmone AA. Mitochondrial DNA analysis of Rhipicephalus sanguineus sensu lato (Acari: Ixodidae) in the Southern Cone of South America. Vet Parasitol. 2012;190:547-55.

8. Dantas-Torres F, Latrofa MS, Annoscia G, Giannelli A, Parisi A, Otranto D. Morphological and genetic diversity of Rhipicephalus sanguineus sensu lato from the New and Old Worlds. Parasit Vectors. 2013:6:213.

9. Hekimoğlu O, Sağlam İ, Özer N, Estrada-Peña A. New molecular data shed light on the global phylogeny and species limits of the Rhipicephalus sanguineus complex. Ticks Tick Borne Dis. 2016;7:798-807.

10. Sanches GS, Évora PM, Mangold AJ, Jittapalapong S, Rodriguez-Mallon A, Guzmán PE, et al. Molecular, biological, and morphometric comparisons between different geographical populations of Rhipicephalus sanguineus sensu lato (Acari: Ixodidae). Vet Parasitol. 2016;215:78-87.
11. Zemtsova GE, Apanaskevich DA, Reeves WK, Hahn M, Snellgrove A, Levin ML. Phylogeography of Rhipicephalus sanguineus sensu lato and its relationships with climatic factors. Exp Appl Acarol. 2016;69:191-203.

12. Filippova NA. Ixodid ticks of subfamily Amblyomminae. Fauna of Russia and neighbouring countries. St. Petersburg: Nauka Publishing House; 1997. 436.

13. Walker JB, Keirans JE, Horak IG. Genus Rhipicephalus (Acari, Ixodidae). A guide to the brown ticks of the world. Cambridge: Cambridge University Press; 2000. 656.

14. Estrada-Peña A, Bouattour A, Camicas JL, Walker AR. Ticks of domestic animals in the Mediterranean region. A guide of identification of species. Zaragoza: University of Zaragoza Press; 2004. 131 pp.

15. Larkin MA, Blackshields G, Brown NP, Chenna R, McGettigan PA, McWilliam $\mathrm{H}$, et al. Clustal W and Clustal X version 2.0. Bioinformatics. 2007;23:2947-8.

16. Kimura M. A simple method for estimating evolutionary rates of base substitutions through comparative studies of nucleotide sequences. J Mol Evol. 1980;16:111-20

17. Tamura K, Stecher G, Peterson D, Filipski A, Kumar S. MEGA6: Molecular Evolutionary Genetics Analysis version 6.0. Mol Biol Evol. 2013;30:2725-9.

18. Hall TA. BioEdit: A user-friendly biological sequence alignment editor and analysis program for Windows 95/98/NT. Nucl Acids Symp Ser. 1999;41:95-8.

19. Coimbra-Dores MJ, Nunes T, Dias D, Rosa F. Rhipicephalus sanguineus (Acari: Ixodidae) species complex: morphometric and ultrastructural analyses. Exp Appl Acarol. 2016;70:455-68

20. Santos-Silva MM, Beati L, Santos AS, De Sousa R, Núncio MS, Melo P, et al. The hard-tick fauna of mainland Portugal (Acari: Ixodidae): an update on geographical distribution and known associations with hosts and pathogens. Exp Appl Acarol. 2011;55:85-121.

21. Otranto D, Huchet JB, Giannelli A, Callou C, Dantas-Torres F. The enigma of the dog mummy from ancient Egypt and the origin of 'Rhipicephalus sanguineus'. Parasit Vectors. 2014;7:2.

22. Szabó MP, Mangold AJ, João CF, Bechara GH, Guglielmone AA. Biological and DNA evidence of two dissimilar populations of the Rhipicephalus sanguineus tick group (Acari: Ixodidae) in South America. Vet Parasitol. 2005; 130:131-40

23. Liu GH, Chen F, Chen YZ, Song HQ, Lin RQ, Zhou DH, et al. Complete mitochondrial genome sequence data provides genetic evidence that the brown dog tick Rhipicephalus sanguineus (Acari: Ixodidae) represents a species complex. Int J Biol Sci. 2013;9:361-9.

24. Cardoso L, Tuna J, Vieira L, Yisaschar-Mekuzas Y, Baneth G. Molecular detection of Anaplasma platys and Ehrlichia canis in dogs from the North of Portugal. Vet J. 2010;183:232-3.

25. Latrofa MS, Dantas-Torres F, Giannelli A, Otranto D. Molecular detection of tick-borne pathogens in Rhipicephalus sanguineus group ticks. Ticks Tick Borne Dis. 2014:5:943-6.

26. Maia C, Ferreira A, Nunes M, Vieira ML, Campino L, Cardoso L. Molecular detection of bacterial and parasitic pathogens in hard ticks from Portugal. Ticks Tick Borne Dis. 2014;5:409-14.

27. Maia C, Casero M, Annoscia G, Latrofa MS, Colella V, Pereira A, et al. Cercopithifilaria sp. II in Vulpes vulpes: new host affiliation for an enigmatic canine filarioid. Parasitol Res. 2017;116:441-3.

28. Cortes HC, Cardoso L, Giannelli A, Latrofa MS, Dantas-Torres F, Otranto D. Diversity of Cercopithifilaria species in dogs from Portugal. Parasit Vectors. 2014;7:26.

29. Moraes-Filho J, Krawczak FS, Costa FB, Soares JF, Labruna MB. Comparative evaluation of the vector competence of four South American populations of the Rhipicephalus sanguineus group for the bacterium Ehrlichia canis, the agent of canine monocytic ehrlichiosis. PLoS One. 2015;10:e0139386. 